\title{
Research on the Evaluation of Talent Agglomeration Effect in 13 Cities of Jiangsu — Based on Dynamic Factor Analysis
}

\author{
Mao Dandan ${ }^{1, a^{*}}$, Gu Ping 2,b \\ ${ }^{1}$ School of Economics and Mana gement, Jiangsu University of Science and Technology, Zhenjiang Jiangsu 212100, \\ China \\ ${ }^{2}$ School of Economics and Management, Jiangsu University of Science and Technology, Zhenjiang Jiangsu 212100, \\ China \\ $a^{*}$ mao_dan_dan@163.com \\ ${ }^{b}$ Frank_ping@163.com
}

\begin{abstract}
With the development of the economy, the speed of technological progress and industrial structure adjustment and upgrading continues to accelerate. The flow of various types of talents shows a trend of agglomeration, and the agglomeration effect is increasingly prominent. On the basis of reviewing existing literature, this article uses panel data from the 13 cities of Jiangsu in the past 10 years to study and construct an evaluation model of talent agglomeration effects in 13 cities of Jiangsu. With the help of dynamic factor analysis, it analyzes the changes in the talent agglomeration effect of 13 cities in recent years as the government has paid more attention to talent work. The results show that in the 10 years of change, the talent agglomeration effect of the 13 cities in Jiangsu has been significantly differentiated, Suzhou has always the strongest talent agglomeration effect, and Suqian is relatively backward. According to the final dynamic evaluation score, the article divides the 13 cities into three types of regions and specifically analyzes the possible reasons that affect the change of talent agglomeration effect, and provides corresponding strategies and suggestions for promoting Jiangsu talent agglomeration, optimizing talent allocation and enhancing the overall competitiveness of the region.
\end{abstract}

Keywords: talent gathering, economy, effect.

\section{INTRODUCTION}

With the progress of society, economic globalization and regional economic integration, human resources have become a strategic resource for the development of the world economy in the 21 st century.

With the development of regional integration, talents are also flowing uninterruptedly, resulting in talent agglomeration. Under certain conditions, it will also produce talent agglomeration effects such as economic effects, scale effects, and innovation effects, which affect regional development.

Jiangsu is one of the first provinces in the Yangtze River Delta and even the whole country to explore the path of "special talent zone". It implements preferential policies for talents such as the "green channel" of talent flow to accelerate the attraction and gathering of high-level talents from all over the world. Compared with other provinces and regions across the country, Jiangsu has advantages in both quantity and quality. However, at the same time, there are still large gaps in social development, technological innovation, industrial structure and humanistic environment among cities and industries in the region. Therefore, with the enhancement of Jiangsu's talent level, how to attract a large number of talents to Jiangsu's urban development, realize talent agglomeration, discover the factors that affect talent agglomeration, promote the sustainable development of regional economy, etc., these issues have become more and more concerned by people. 


\section{RELATED RESEARCH AT HOME AND ABROAD}

There are few foreign researches on the evaluation of talent agglomeration effects, and the main focus is on domestic scholars. In the domestic research on the evaluation index system of talent aggregation effect, Tongquan Zhang (2008) includes 10 items from the scale of aggregation, talent structure, talent flow, talent growth, virtual talent, talent use, talent innovation, talent linkage, talent attraction, and talent satisfaction. On the one hand, an index evaluation system for the effect of talent agglomeration was constructed ${ }^{[1]}$. Xingzhen Zhu , Caihong Zhu (2011) based on the realistic characteristics of talent agglomeration and the reality of talent agglomeration in Zhejiang Province, establishing a talent agglomeration from six aspects: talent scale, talent flow, talent utilization, talent innovation, talent linkage and talent attraction. Effect evaluation index system $^{[2]}$. Jianwu Chen, Lu Lin, etc. (2018) established a talent agglomeration effect evaluation index system based on five indicators: economic strength, living standards, cultural education, infrastructure, and technological level ${ }^{[3]}$.

In terms of the research on the evaluation method of talent agglomeration effect, Tongquan Zhang and Lejie Wang (2009) based on three manufacturing bases, used principal component analysis to convert multiple evaluation indicators of talent agglomeration effect into three indicators: economic effect and scale effect indicator, innovation Effect indicators, talent growth indicators ${ }^{[4]}$. Yong Wang (2011) used the panel data of 13 prefecture-level cities in Jiangsu in 2009 and selected 13 measurement variables using principal component analysis to compare and analyze the agglomeration effects of scientific and technological talents in 13 cities in Jiangsu. The talent agglomeration effect index can be classified into two main components: economic development effect and social development effect ${ }^{[5]}$. Chonghuai Niu, Juan Huang, Qiuxia Li, etc. (2013) used six central provinces as the object to compare the talent accumulation effect with the gray correlation model, and concluded that Hubei Province's scientific and technological talent accumulation effect is the highest among the six provinces ${ }^{[6]}$.

Regarding the research on the evaluation of talent agglomeration effects, scholars have established appropriate evaluation systems from their respective research perspectives, which mainly cover economic effects, living environment, innovation effects, scale effects, and social environment. In terms of research methods, there are many studies using factor analysis methods, but they all focus on static research based on cross-sectional data. The lack of research on panel data makes it impossible to intuitively judge the changes in the talent agglomeration effect in recent years. With reference to the indicators established by scholars, this article will establish initial indicators from the five perspectives of economic effect, talent living environment, innovation effect, scale effect, and social and humanistic environment. Taking into account that traditional factor analysis itself is insufficient in interpretation of panel data research, This paper uses dynamic factor analysis, a new method, to study the effect of talent agglomeration in Jiangsu with panel data.

\section{RESEARCH ON THE EVALUATION OF EVALUTION OF TALENT AGGLOMERATION EFFECT IN 13 CITIES OF JIANGSU}

\subsection{Sample selection and data acquisition}

This paper selects the data of 13 cities in Jiangsu from 2009 to 2018 as the sample. The data is taken from the "Jiangsu Statistical Yearbook (2010-2019)" and the statistical yearbooks of each city, as well as the work reports of the municipal governments.

\subsection{Research Method}

Dynamic factor analysis is a multivariate statistical method, which combines the cross-sectional results obtained by principal component analysis and the time series results obtained by linear regression, and then analyzes them later. This comprehensively considers the three factors of sample, variables and time, and is suitable for many fields such as biopharmaceuticals, management, economics.

Specific steps are as follows:

(1) Standardize data processing to eliminate the influence of different dimensions;

(2) Based on the annual covariance matrix $S(t)$, Based on the annual covariance matrix

$$
S_{T}=\frac{1}{T} \sum_{t=1}^{T} S(t)
$$

(3) Find the eigenvalues and eigenvectors of $S_{T}$, as well as the common factor variance contribution rate and cumulative variance contribution rate;

(4) Take the number of principal components k, and extract the principal components $\mathrm{F} 1, \mathrm{~F} 2, \ldots, \mathrm{Fk}$;

(5) Calculate the static score matrix of the selected sample;

$$
c_{i h}=\left(\bar{z}_{i}-\bar{z}_{\mathrm{n}}\right)^{\prime} \times a_{h}
$$

among them, ${ }^{a_{h}}$ is the eigenvector of the average variance-covariance matrix $S_{T}$, $\bar{z}_{i}=\frac{1}{T} \sum_{t=1}^{T} z_{i t}, i=1_{m} l, \bar{z}_{n}=\frac{1}{l} \sum_{i=1}^{l} \bar{z}_{i}, z_{i t}^{\prime}=\left(z_{i 1 t}, \ldots, z_{i j t}\right), i=1_{m} l, t=1_{m} T$

(6) Calculate the dynamic score matrix of each 
sample for each year, and calculate the dynamic score of each sample according to the extracted principal components and the corresponding variance contribution rate;

$$
\begin{aligned}
& c_{i h t}=\left(z_{i t}-\bar{z}_{i t}\right)^{\prime} \times a_{h}, h=1 \ldots K, t=1 \ldots T \\
& \text { among them, } z_{i t}=\frac{1}{I} \sum_{i=1}^{I} z_{i t} .
\end{aligned}
$$

(7) Calculate the average composite score

$$
E=\frac{1}{T} \sum c_{i h t}
$$

\subsection{Variable Selection}

The talent agglomeration effect is actually difficult to obtain directly, so it is difficult to directly evaluate it objectively. Many domestic scholars grasp the characteristics of talent agglomeration effect through reasonable interpretation of indicators. Therefore, in this article, the effect of talent accumulation can be considered from two aspects. First, the effect of talent agglomeration can only occur when certain foundations and conditions are met. Therefore, it can be considered from economic, social, environmental and other aspects to select indicators. Second, a series of changes that will occur after the talent agglomeration effect occurs, such as affecting the quality of life of individuals and changes in the social environment, so the affected factors can also be used as indicators. Through the above analysis and referring to previous studies and the availability of data, the following indicators are selected as shown in Table 1 to construct the evaluation indicators of talent

\begin{tabular}{|c|c|c|}
\hline target & First-level index & Secondary indicators \\
\hline \multirow{5}{*}{$\begin{array}{l}\text { Evaluation } \\
\text { System of } \\
\text { Talent } \\
\text { Agglomeration } \\
\text { Effect }\end{array}$} & Economic Effects & $\begin{array}{l}\text { Regional GDP, GDP per capita, proportion of tertiary industry in GDP, } \\
\text { general public budget revenue, foreign direct investment }\end{array}$ \\
\hline & Talent quality of life & $\begin{array}{l}\text { Per capita disposable income of urban residents, per capita consumption } \\
\text { expenditure of urban residents, per capita housing area of urban residents }\end{array}$ \\
\hline & Scale effect & $\begin{array}{l}\text { Number of industrial enterprises, number of universities, number of } \\
\text { employees }\end{array}$ \\
\hline & Innovation effect & $\begin{array}{l}\text { The number of patent applications, the number of patents granted, the } \\
\text { proportion of research and development expenditures in GDP, the } \\
\text { proportion of the output value of high-tech industries in the province, and } \\
\text { the proportion of the output value of high-tech industries in the output value } \\
\text { of industries above designated size }\end{array}$ \\
\hline & $\begin{array}{l}\text { Society and Humanities } \\
\text { surroundings }\end{array}$ & $\begin{array}{l}\text { Per capita urban road area, per capita park and green area, number of public } \\
\text { library institutions, public library book collection, number of public health } \\
\text { institutions, health technicians, number of health service beds, public } \\
\text { transportation vehicles per } 10,000 \text { people, Internet users }\end{array}$ \\
\hline
\end{tabular}
agglomeration effect.

Table1 Indicators of talent agglomeration effect

\section{DATA PROCESSING AND ANALYSIS}

This paper adopts the dynamic factor analysis method, with the help of STATA15.1 tools, to standardize the data, solve the average

Table 2 Eigenvalues of common factors, variance contribution rate and cumulative variance contribution rate

\begin{tabular}{|c|c|c|c|}
\hline Common factor & Eigenvalues & Variance contribution rate & Cumulative variance contribution rate \\
\hline F1 & 126.97378 & 0.59834763 & 0.59834763 \\
\hline F2 & 26.743169 & 0.12602375 & 0.72437138 \\
\hline F3 & 21.021863 & 0.09906283 & 0.8234342 \\
\hline F4 & 10.007759 & 0.04716028 & 0.87059448 \\
\hline
\end{tabular}

It can be seen from the running results of Table 2 that the eigenvalues of the first four principal components are 126.97378, 26.743169, 21.021863, and 10.007759, which are far greater than 1 , and the variance contribution rates of these four principal components are $59.83 \%, 12.60 \%, 9.91 \%$ and $4.72 \%$, the cumulative contribution rate reached $87.06 \%$ (already greater than $>85 \%$ ), so the four principal components extracted can be used to represent the level of talent agglomeration effect in 13 cities in Jiangsu. Then take variance-covariance matrix, and obtain the eigenvalues, eigenvectors, the variance contribution rate and cumulative variance contribution rate of each principal component. The results are shown in Table 2.

the proportion of the variance contribution rate of the four main factors to the cumulative variance explanation rate as the weight to obtain a comprehensive evaluation function for the talent agglomeration effect in Jiangsu:

$$
\mathrm{F}=0.59835 \mathrm{~F} 1+0.12602 \mathrm{~F} 2+0.09906 \mathrm{~F} 3+0.04716 \mathrm{~F} 4
$$

According to steps 6 and 7, the dynamic scores and average comprehensive scores of the talent agglomeration effect of 13 cities in Jiangsu from 2009 to 2018 can be obtained, and the average comprehensive 
scores are ranked (see Table 3 ). If the score $\bar{E} \geq 1$, it means the talent agglomeration effect in the region is obvious; if $-1 \leq \overline{\mathrm{E}}<1$, it means the talent agglomeration effect in the region is average; if $\overline{\mathrm{E}}<-1$, it means the talent agglomeration effect in the region is weak . Based on this, the 13 urban areas in Jiangsu are classified according to the average comprehensive score of their talent agglomeration effect. That is, Suzhou, Nanjing, and Wuxi are the first-class regions, and their talent agglomeration effect is at the upper reaches of Jiangsu;
Nantong, Changzhou, Zhenjiang, and Yangzhou, Xuzhou is the second type of region, and its talent agglomeration effect is in the middle reaches of Jiangsu; the third type of region has a weaker talent agglomeration effect and is in the lower reaches of Jiangsu, mainly including Taizhou, Yancheng, Huai'an, Lianyungang and Suqian. .

Table3 Total scores of talent agglomeration effect evaluation in 13 cities in Jiangsu

\begin{tabular}{|c|c|c|c|c|c|c|c|c|c|c|c|c|}
\hline Year & 2009 & 2010 & 2011 & 2012 & 2013 & 2014 & 2015 & 2016 & 2017 & 2018 & Average Score & Rank \\
\hline Suzhou & 4.75 & 4.83 & 5.10 & 5.87 & 5.58 & 5.14 & 5.00 & 5.21 & 5.43 & 6.01 & 5.29 & 1 \\
\hline Nanjing & 1.98 & 2.04 & 2.24 & 1.91 & 2.26 & 2.17 & 2.60 & 2.74 & 2.62 & 3.01 & 2.36 & 2 \\
\hline Wuxi & 1.57 & 1.86 & 1.97 & 2.19 & 1.82 & 1.46 & 1.69 & 1.69 & 1.74 & 1.92 & 1.79 & 3 \\
\hline Nantong & 0.26 & 0.41 & 0.58 & 0.47 & 0.56 & 0.74 & 0.90 & 1.02 & 1.24 & 1.01 & 0.72 & 4 \\
\hline Changzhou & 0.48 & 0.44 & 0.17 & 0.38 & 0.36 & 0.41 & 0.24 & 0.29 & 0.24 & 0.03 & 0.30 & 5 \\
\hline Zhenjiang & -0.51 & -0.52 & -0.53 & -0.50 & -0.36 & -0.34 & -0.39 & -0.54 & -0.67 & -0.85 & -0.52 & 6 \\
\hline Yangzhou & -0.16 & -0.20 & -0.46 & -0.66 & -0.79 & -0.74 & -0.77 & -0.79 & -0.74 & -0.68 & -0.60 & 7 \\
\hline Xuzhou & -0.82 & -0.79 & -0.57 & -0.74 & -0.50 & -0.44 & -0.60 & -0.60 & -0.77 & -0.94 & -0.68 & 8 \\
\hline Taizhou & -1.01 & -0.99 & -1.04 & -1.07 & -1.18 & -1.08 & -1.02 & -1.03 & -0.89 & -0.86 & -1.02 & 9 \\
\hline Yancheng & -1.37 & -1.48 & -1.45 & -1.40 & -1.38 & -1.28 & -1.39 & -1.29 & -1.24 & -1.25 & -1.35 & 10 \\
\hline Huai'an & -1.84 & -1.84 & -1.84 & -1.98 & -1.98 & -1.82 & -1.92 & -2.04 & -2.10 & -2.15 & -1.95 & 11 \\
\hline Lianyungang & -1.40 & -1.60 & -1.82 & -2.08 & -2.06 & -2.00 & -2.06 & -2.15 & -2.23 & -2.46 & -1.98 & 12 \\
\hline Suqian & -1.94 & -2.16 & -2.35 & -2.38 & -2.33 & -2.23 & -2.28 & -2.50 & -2.63 & -2.79 & -2.36 & 13 \\
\hline
\end{tabular}

1. According to the above research, the following results can be obtained:

By comparing the average comprehensive scores of the talent agglomeration effect of 13 cities in Jiangsu from 2009 to 2018 , we can find that, first, the 13 cities of Jiangsu are divided into three types of regions based on the average comprehensive scores. The first type of region has a strong talent agglomeration effect, and the second type of region Moderate, while the talent agglomeration effect in the third category is relatively weak. Among them, the first category of regions only includes three cities, Suzhou, Nanjing, and Wuxi, that is, 10 cities have a mid-to-lower talent agglomeration effect, and these three cities are all in southern Jiangsu. Except for Taizhou in the third category, the other four cities are all in northern Jiangsu.

Second, the talent agglomeration effect in Jiangsu is unbalanced, and there is a significant gap between regions. First of all, from the perspective of average comprehensive scores, the average comprehensive scores of the first type of regions basically remained at around 3.15 , while the average comprehensive scores of the second and third types of regions remained at around -0.15 and -1.73 , respectively, significantly lower than the first class area. Secondly, by comparing the average comprehensive scores of 13 cities in Jiangsu from 2009 to 2018 , it can be found that in the past ten years, Suzhou, Nanjing and Wuxi have been among the top three in Jiangsu in terms of talent agglomeration effects, and are in an advantageous position in Jiangsu Province; while Suqian and Lianyungang, Huai'an ranks the bottom three in the talent agglomeration effect of Jiangsu. Compared with Suzhou, Nanjing and Wuxi, the talent agglomeration effect is quite different.

Third, the three types of regional talent agglomeration effects have different changes in the past ten years. According to the average comprehensive score, Jiangsu is divided into three major regions. The urban talent agglomeration effect in the first category of regions has a short-term downward trend in the middle, and then rises, and finally increases compared with ten years ago. Among them, especially The growth rates of Suzhou and Nanjing are more obvious, while Wuxi is relatively flat; the talent agglomeration effect of the second type of area is in a dynamic change, except for Nantong, which is generally increasing, the other cities in the second area have a downward trend; and the third type of area The talent agglomeration effect of cities in these regions has shown a continuous downward trend. Taizhou and Yancheng have increased slightly, while the other three cities are all declining. Based on this speculation, Jiangsu's talent agglomeration effect is showing a trend of polarization. If it continues, Jiangsu's talent agglomeration effect will be in an extreme situation where the strong will become stronger and the weak will become weaker. 
2. In view of the above results, give specific explanations and possible reasons in three types of regions:

The first type of regions: Suzhou, Nanjing and Wuxi. Figure 1 shows the scatter diagram of changes in the talent agglomeration effect in the first type of region. First of all, the three cities of Suzhou, Nanjing and Wuxi have strong economic strength among the 13 cities in Jiangsu. At the same time, the governments of the three cities also attach great importance to attracting and retaining talents, and their geographical locations also have comparative advantages. Generally speaking, talents are more inclined to choose economic development. The development of cities with better and superior environments has resulted in a phenomenon that the talent agglomeration effect of these three cities is higher than that of other cities in Jiangsu. However, the talent agglomeration effects of these three cities are somewhat different.

Suzhou has the highest overall score in the past years, and the overall trend is on the rise. From November 2010, Suzhou issued the "Outline of Jiangsu Province Medium and Long-term Talent Development Plan (2010-2020)" to March 2011, "Suzhou City's Medium and Long-term Talent Development Plan Outline (2011-2020)", and a series of Talent introduction policy. At the same time, Suzhou also has a geographical advantage very close to Shanghai. It can enjoy lower housing prices and lower living costs at a salary level slightly lower than that of Shanghai, and the platform and space for Suzhou to display its talents is not inferior to that of Shanghai. Some talents who originally chose Shanghai were willing to go to Suzhou. In addition, a large number of well-funded and technologically advanced enterprises have emerged in Suzhou, and the social welfare benefits provided are relatively high, attracting a large number of talents from other regions, leading to an increase in the talent gathering effect in 2011. Later, due to the large influx of talents in a short period of time, and some talents also saw other cities in Jiangsu attracting talents, they moved to other cities, resulting in a decrease in the talent agglomeration effect in 2013, and because of Suzhou's human capital, the advantages of transportation location and industrial supporting facilities have slowly increased the talent gathering effect.

For Nanjing, the talent agglomeration effect is significantly lower than that of Suzhou. The reason may be that although Nanjing's higher education strength is the strongest in Jiangsu Province, it has not maximized the advantages of science and education resources into talent advantages. Graduates who stay in Nanjing during the graduation season each year There are fewer students. On the one hand, because Nanjing does not have a better industrial cluster, there are not many suitable job opportunities for these graduates. On the other hand, it is also related to Nanjing's low income and high housing prices. However, as Nanjing has become more and more aware of the importance of talents in recent years, and adopted a series of talent subsidy policies to attract and retain talents, its talent agglomeration effect has gradually improved. In the long run, Nanjing's industry is highly comprehensive but lacks agglomeration effect. It is necessary to vigorously cultivate innovative leading enterprises, and at the same time build high-growth enterprises, especially software, technology, etc., so as to form an industrial agglomeration effect and make it reach a certain level. Scale, thus forming a scale effect, which is more attractive to talents.

Wuxi and Suzhou have similar volatility, but the degree of volatility is relatively small. Its talent agglomeration effect is not only much lower than that of Suzhou, but also lower than that of Nanjing except for 12 years. The reason may be due to Wuxi's science, education, industry, urban commercial scale, and infrastructure. In other respects, Wuxi lags behind Nanjing, but compared with Nanjing and Suzhou, Wuxi has less pressure to buy a house and less employment pressure. In terms of living environment and facilities, Wuxi is also more livable, so it can use the "spillover effect" to attract talents. Agglomeration, finally showing the result of an improved talent agglomeration effect.

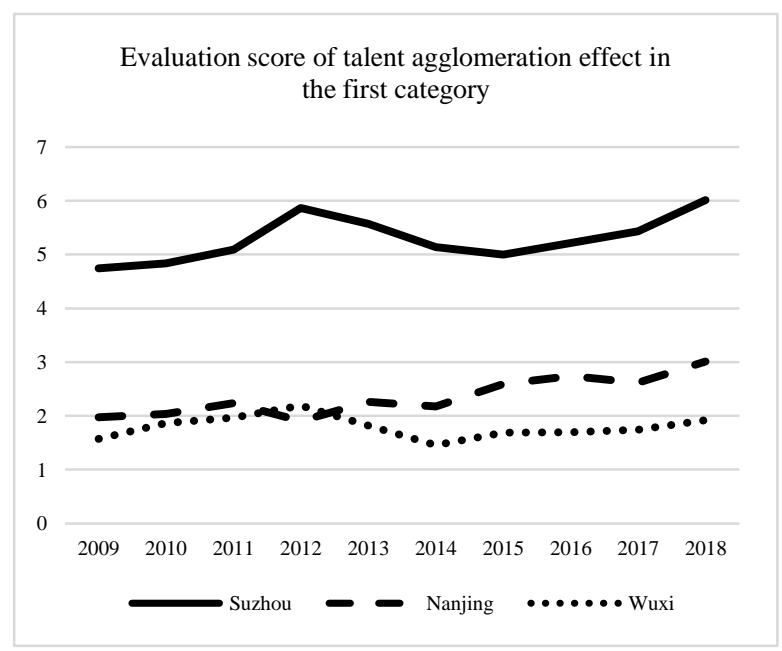

Figure.1 Scatter diagram of the evaluation of talent agglomeration effect in the first type of region

The second category: Nantong, Changzhou, Zhenjiang, Yangzhou, and Xuzhou. Figure 2 shows the scatter diagram of changes in the effect of talent agglomeration in the second category. Except for Nantong, these areas have declined in general. Nantong showed a steady increase from 2009 to 2017, and began to decline suddenly in 2017 . The reason for the strong talent agglomeration effect of Nantong may be that Nantong is backed by Shanghai, an international metropolis, and is exposed to strong economic radiation. Coupled with the ever-increasing industrial chain, it can 
attract talents to integrate, and the talent agglomeration effect has increased, but then due to Nantong Factors such as rising housing prices and the continuous negative growth of the local population for more than ten years have affected the talent inflow rate in the past two years.

Although Changzhou and Zhenjiang are located in southern Jiangsu, their talent agglomeration effect is generally declining, indicating that Changzhou and Zhenjiang have not been able to attract more talents in the past 10 years. With the release of talent introduction policies in various cities, more talents are not because of the overall improvement in the talent introduction policies of these two cities, but are attracted by other cities with better economies. The reason may be that Changzhou and Zhenjiang have fewer high-tech industries and industrial transformation is relatively difficult, which is not enough to attract more talents. With the current situation of "grabbing talents" everywhere, the government needs to pay more attention to attracting and retaining talents. As a carrier of talent work, enterprises support more enterprises, seize the geographical advantages of the two cities, and attract more talents to integrate.

Yangzhou is located in the central Jiangsu region, and its talent gathering effect is also showing a downward trend. The reason may be that Yangzhou's industry is underdeveloped. By the end of 18 years, Yangzhou's railway construction is backward and lack of obvious pillar industries. In addition, all parts of the country have adopted talent recruitment and retention of talents. Policies and talents tend to move to cities like Suzhou, Nanjing, and Wuxi, which have stronger economic strength and relatively larger development space. Therefore, the talent agglomeration effect of Yangzhou has not been improved accordingly.

Although Xuzhou is located in the northern part of Jiangsu, it ranks into the second category. First of all, Xuzhou is located at the junction of Jiangsu, Shandong, Henan, and Anhui. Xuzhou has an excellent transportation location, many important railways need to transit in Xuzhou, and Xuzhou has a solid industrial foundation, developed heavy industry, and has a certain industrial strength, and the local government has made great efforts in attracting talents and improving the talent environment. However, compared with cities in southern Jiangsu, Xuzhou still has economic and geographic advantages, so the talent agglomeration effect has not been improved on the whole.

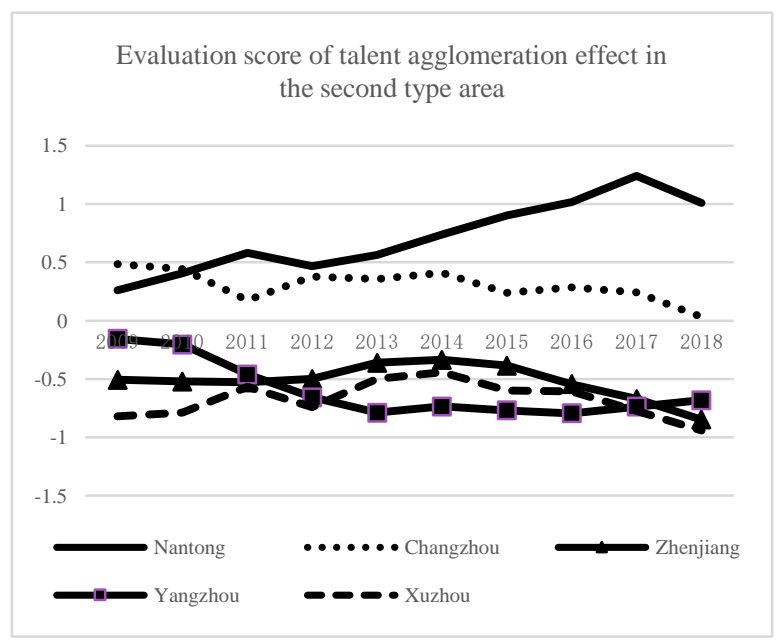

Figure.2 Scatter diagram of the evaluation of talent agglomeration effect in the second type of region

The third category: Taizhou, Yancheng, Huai'an, Lianyungang and Suqian. Figure 3 shows the scatter diagram of the changes in the talent agglomeration effect in the third category. Suqian has the lowest overall score in the past years, and the overall trend is also decreasing. The reason may be that the overall economic strength of Suqian is insufficient, the high-tech industry is also insufficient, and there is no geographical advantage to attract talents.

Lianyungang has the largest decline, and Huai'an has a slight decline, which shows that the two cities are insufficient in attracting and retaining talents. It is not enough to simply introduce a welfare policy to attract talents. Special industries should be developed according to local conditions and an industrial brand with the city's logo should be developed, using consolidate talent gathering power with industry.

Yancheng has a slight increase, from the same starting point as Lianyungang in 2009 to far surpassing Lianyungang in 18 years. The reason for the analysis may be that Yancheng has successively launched a series of talent policies in recent years, such as the "515 Talent Attraction Program", 10 innovations in science and technology, and 10 new talents policies in Yancheng. In addition, Yancheng is also the only city in northern Jiangsu that is included in the 27 cities in the integrated central area of the Yangtze River Delta. Although Yancheng is the northernmost among the 27 cities in the central area of the Yangtze River Delta, it has no geographical advantage and does not have close communication with the Jiangnan area. However, with the improvement of traffic conditions, Yancheng is slowly developing and attracting more attention. Many talents are integrated.

While Taizhou is located in the central Jiangsu region but in the third category, it can be found that the talent agglomeration effect has increased slightly, and the effect evaluation score in 2018 has been> -1 , 
indicating that although Taizhou has a poor talent agglomeration effect in previous years, In recent years, Taizhou has actively responded to the strategic layout of local industrial development, closely relying on the advantages of local biomedical industry clusters, implemented the strategy of "targeting talents", vigorously introduced talents in the biomedical field, and created a very high profile like Yangzijiang Pharmaceutical Group. National leading enterprises with innovative capabilities provide strong talent guarantee for the development of local advantageous industries and characteristic industries, thereby attracting and retaining some talents, and the talent agglomeration effect is improved.

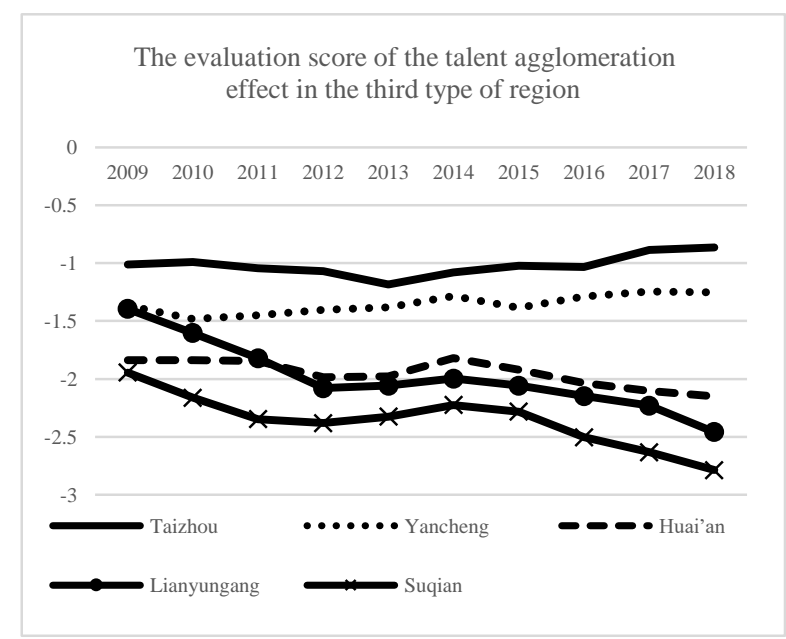

Figure.3 Scatter diagram of the evaluation of talent agglomeration effect in the third type of region

\section{CONCLUSION AND SUGGESTION}

Based on the panel data of 13 cities in Jiangsu from 2009 to 2018 , this paper uses dynamic factor analysis to analyze their talent agglomeration effect level. The results show that: (1) The talent agglomeration effect of the 13 cities in Jiangsu is significantly different. The first type of region (Suzhou, Nanjing, Wuxi) has a strong talent agglomeration effect, and the second type of region (Nantong, Changzhou, Zhenjiang, Yangzhou, Xuzhou) is moderate, while the talent agglomeration effect of the third type of regions (Taizhou, Yancheng, Huai'an, Lianyungang, Suqian) is relatively weak; (2) The talent agglomeration effect of the three types of regions has changed in ten years. It is found that Suzhou, Nanjing, and Wuxi The talent agglomeration effect of economically developed regions is obvious, and it has been increasing in recent years, while for cities with weak economic development, such as Suqian, Lianyungang, Huai'an, etc., the talent agglomeration effect is not obvious, and it is being introduced everywhere. Under the environment of the talent introduction policy, there is still no way to promote the enhancement of the talent gathering effect. Talent agglomeration and regional economic development conditions interact with each other. The talent agglomeration effect is a comprehensive reflection of the regional economy and social environment after a large number of the same industry has formed agglomeration phenomenon in a certain area after the flow of talents. The level of development also affects the attractiveness of the region to talents, which in turn affects the concentration of talents, which in turn will have an impact on the socio-economic development of the region. If things go on like this, the talent agglomeration effect in Jiangsu will definitely be in an extreme situation where the strong will become stronger and the weak will become weaker. Therefore, this article proposes the following recommendations :

(1) Clearly establish a correct view of talents. All cities should attach importance to the subject status of talents, not only for academic qualifications, not only for professional titles, not only for qualifications, not only for identity. The government should provide the environment and conditions for all kinds of professionals to give full play to their abilities, so that their talents can be used to a greater extent. Therefore, each city should formulate a reasonable talent introduction policy based on its own positioning, adapt measures to local conditions, introduce a group of truly powerful, capable, and potential talents, eliminate identity discrimination and policy barriers in the flow of talents, reduce the resistance to talent gathering, and attract the economy of each city. Develop all kinds of talents needed, give full play to talent creation ability, and provide all kinds of talents with opportunities for growth and a stage for display.

(2) Give full play to the leading role of superior companies. Enterprise is the carrier of talent employment, talent is the main body of talent agglomeration, and industrial agglomeration is the geographic concentration of enterprises operating in the same industry. Without a strong corporate group, industrial agglomeration cannot be realized. Industrial agglomeration can attract talents, which can further promote industrial agglomeration. The economic development of each city in Jiangsu has its own local characteristics. Each city sorts out the characteristic industries in the region, formulates the key points for attracting talents from the perspective of "top-level design", gathers high-end talents with leading industrial clusters, and cultivates a number of industry-leading enterprises , And give key support. In the end, we will strive to form a good situation in which talents lead the industry, the industry gathers talents, and the enterprise interacts positively.

(3) Pay attention to the development environment of talents. General Secretary $\mathrm{Xi}$ pointed out: "If the environment is good, the talents will gather and the career will be prosperous; if the environment is not good, 
the talents will be scattered and the career will be declining." This is enough to explain the importance of the talent development environment to the talent gathering. The talent development environment is the basis for attracting, retaining and developing talents. To play the role of talent agglomeration, it is necessary to continuously improve regional infrastructure, improve the ecological environment, further optimize the living environment of talents, and provide a platform for talents to display their talents. Improve the satisfaction of talents with the work and life service environment, strive to reduce the turnover rate of talents, and improve the level of talent gathering. All cities are working hard to improve the talent development environment and serve talents with high-quality environments, so that talents can be introduced, retained, and used well.

\section{REFERENCES}

[1] Tongquan Zhang. Research on the Evaluation Index System of Talent Agglomeration Effect[J]. Modern Management Science, 2008, 000(008):83-84.

[2] Xingzhen Zhu, Caihong Zhu. Construction of Evaluation Indexes for Talent Agglomeration Effects: Based on the Case of Zhejiang Province[J]. Journal of Fujian Provincial Committee Party School of the Communist Party of China, 2011(10):102-106.

[3] Jianwu Chen, Lu Lin. Evaluation of the Agglomeration Effect of High-level Innovative and Entrepreneurial Talents in Fujian Province[J]. Theoretical Research and Practice of Innovation and Entrepreneurship, 2018, 001(022):17-21.

[4] Tongquan Zhang, Lejie Wang. Evaluation of the Talent Agglomeration Effect of my country's Manufacturing Base__Based on the Comparative Analysis of Three Manufacturing Bases[J]. China Soft Science, 2009(11):64-71.

[5] Yong Wang.An Empirical Study on the Agglomeration Effect of Scientific and Technological Talents_Based on Jiangsu Data[J]. Science and Technology Management Research, 2011, 031(005):153-15.

[6] Chonghuai Niu, Juan Huang, Qiuxia Li. The measurement of the accumulation effect of scientific and technological talents based on the grey relational projection model: Taking the six provinces of central China as examples[J]. Science \& Technology Progress and Policy, 2013, 030(001):150-154. 